\title{
Physicochemical Stability of Enriched Phenolic Fractions of Cyclopia genistoides and ex vivo Bi-directional Permeability of Major Xanthones and Benzophenones
}

Authors

Neil Miller ${ }^{1,2}$, Christiaan Johannes Malherbe ${ }^{1}$, Werner Gerber ${ }^{3}$, Josias H. Hamman ${ }^{3}{ }^{(\mathbb{C}}$, Marieta van der Rijst ${ }^{4}$, Marique Aucamp ${ }^{5}$, Elizabeth Joubert ${ }^{1,2}$ (D)

Affiliations

1 Plant Bioactives Group, Post-Harvest and Agro-processing Technologies, Agricultural Research Council (ARC) Infruitec-Nietvoorbij, Stellenbosch, South Africa

2 Department of Food Science, Stellenbosch University, Stellenbosch, South Africa

3 Centre of Excellence for Pharmaceutical Sciences, North-West University, Potchefstroom, South Africa

4 Biometry Unit, Agricultural Research Council, Stellenbosch, South Africa

5 School of Pharmacy, University of the Western Cape, Bellville, South Africa

Key words

Ex vivo intestinal transport, xanthones, benzophenones, Cyclopia genistoides, Fabaceae, honeybush

$\begin{array}{ll}\text { received } & \text { May 21, 2020 } \\ \text { accepted after revision } & \text { September 14, 2020 } \\ \text { published online } & \text { November 3, 2020 }\end{array}$

Bibliography

Planta Med 2021; 87: 325-335

DOI $10.1055 / \mathrm{a}-1265-1945$

ISSN 0032-0943

(c) 2020. Thieme. All rights reserved.

Georg Thieme Verlag KG, Rüdigerstraße 14,

70469 Stuttgart, Germany

Correspondence

Prof. Elizabeth Joubert

Plant Bioactives Group, Post-Harvest and Agro-Processing Technologies, Agricultural Research Council (ARC) InfruitecNietvoorbij

Private Bag X5026, Helshoogte Road,

7599 Stellenbosch, South Africa

Phone: + 27218093444 , Fax: + 27218093430

JoubertL@arc.agric.za

Supplementary material is available under

https://doi.org/10.1055/a-1265-1945

\section{ABSTRACT}

Fractions of an ultrafiltered Cyclopia genistoides extract, respectively enriched in xanthones and benzophenones, were previously shown to inhibit mammalian $\alpha$-glucosidase in vitro. The present study investigated ex vivo intestinal transport of these fractions, using excised porcine jejunal tissue, to determine whether the gut could be a predominant in vivo site of action. The major bioactive compounds, the xanthones (mangiferin, isomangiferin) and benzophenones (3- $\beta$-D-glucopyranosyliriflophenone, 3- $\beta$-D-glucopyranosyl-4-O- $\beta$-D-glucopyranosyliriflophenone) exhibited poor permeation in the absorptive direction with a relatively high efflux ratio (efflux ratio > 1). The efflux ratio of 3- $\beta$-D-glucopyranosyl-4- $O$ - $\beta$-D-glucopyranosyliriflophenone (3.05) was similar to rhodamine 123 (2.99), a known substrate of intestinal P-glycoprotein 1 efflux transporters. Low epithelial membrane transport rates, coupled with efflux mechanisms, would effectively concentrate these bioactive compounds at the target site (gut lumen). Storage stability testing and moisture sorption assays of the xanthone-enriched fraction, benzophenone-enriched fraction, and ultrafiltered Cyclopia genistoides extract were performed to determine their susceptibility to physical and chemical degradation during storage. Hygroscopicity of the powders, indicated by moisture uptake, decreased in the order: benzophenone-enriched fraction $(22.7 \%)>$ ultrafiltered Cyclopia genistoides extract $(14.0 \%)>$ xanthone-enriched fraction (10.7\%). 3- $\beta$-D-Glucopyranosylmaclurin, a minor benzophenone, was the least stable of the compounds, degrading faster in the benzophenone-enriched fraction than in ultrafiltered Cyclopia genistoides extract, suggesting that the ultrafiltered extract matrix may provide a degree of protection against chemical degradation. Compound degradation during 12 wk of storage at $40^{\circ} \mathrm{C}$ in moisture-impermeable containers was best explained by first order reaction kinetics. 


$\begin{array}{ll}\text { ABBREVIATIONS } \\ \text { AGI } & \text { alpha-glucosidase inhibitor } \\ \text { BEF } & \text { benzophenone-enriched fraction } \\ \text { ER } & \text { efflux ratio } \\ \text { GIT } & \text { gastrointestinal tract } \\ \text { I3G } & \text { 3- } \beta \text {-D-glucopyranosyliriflophenone } \\ \text { IDG } & \text { 3- } \beta \text {-D-glucopyranosyl-4-O- } \beta \text {-D-glucopyrano- } \\ & \text { syliriflophenone } \\ \text { M3G } & \text { 3- } \beta \text {-D-glucopyranosylmaclurin } \\ P_{\text {app }}^{\text {AB }} & \text { apparent permeability coefficient in the } \\ & \text { absorptive direction } \\ P_{\text {app }}^{\text {BA }} & \text { apparent permeability coefficient in the } \\ \text { TEER } & \begin{array}{l}\text { secretory direction } \\ \text { trans-epithelial electrical resistance }\end{array} \\ \text { UCGE } & \text { ultrafiltered Cyclopia genistoides extract } \\ \text { XEF } & \text { xanthone-enriched fraction }\end{array}$

\section{Introduction}

Various phytochemicals have gained attention because of remarkable in vitro bioactivity, but many promising lead compounds may be unsuitable candidates for nutraceutical development because of low systemic bioavailability (i.e., failure to reach and maintain therapeutic plasma concentrations) [1]. However, low bioavailability of bioactive compounds is of less concern when the therapeutic target is located in the GIT itself, as opposed to compounds that require systemic bioavailability through intestinal absorption to achieve therapeutic plasma concentrations [2].

The close interrelationship between diet and metabolic disorders such as obesity and type 2 diabetes mellitus has created opportunities for the development of antidiabetic functional food ingredients or nutraceuticals as adjuncts to first-line treatments such as lifestyle modification and pharmacotherapy [3]. In this context, the search for natural AGIs, which inhibit the enzymatic digestion of dietary carbohydrates in the small intestine, thereby preventing postprandial hyperglyaemia, is warranted. Promising natural AGIs represent large chemical diversity and include polyphenols [4].

Previously, we confirmed in vitro AGI activity for several of the major phenolic compounds in the herbal tea, Cyclopia genistoides (L.) Vent. (Family: Fabaceae; Tribe: Podalyrieae) ( $\triangleright$ Fig. 1) (i.e., mangiferin, isomangiferin, I3G, and IDG), as well as for the minor benzophenone, M3G, $[5,6]$ as part of an ongoing development of an antidiabetic nutraceutical extract and/or XEF and BEF, respectively $[6,7]$. Studies in the pig [8], rat [9], and human [10] confirmed that mangiferin is poorly bioavailable. Ex vivo transport studies, using porcine small intestine, also showed low bioavailability for mangiferin as well as for isomangiferin [11, 12], I3G, and IDG [12]. A methanolic extract of $C$. subternata Vogel and a hydroethanolic extract of $C$. genistoides were used in the respective studies. In the present study, we revisited the intestinal permeability of the major xanthones and benzophenones of $C$. genistoides, since extract composition could affect transport of compounds across the intestinal membrane. Tian et al. [13] demonstrated that in vivo intestinal absorption of mangiferin in rats was higher when present in a Rhizoma Anemarrhenae extract compared to purified mangiferin.

Another important consideration in the development of a functional food or nutraceutical ingredient is the shelf-life of intermediate products, as poor stability would affect the efficacy. Stability tests are employed to gain an understanding of chemical stability of compounds during bulk storage. A study on a spraydried C. subternata hot water extract demonstrated that the degradation of mangiferin, isomangiferin, and IMG, among others, followed a pseudo-first order reaction model and that the composition of the product affected the degradation rate constants [14]. Compositional differences between the ultrafiltered C. genistoides extract and semi-purified fractions are therefore expected to affect their chemical stability.

The present study aimed to evaluate the intestinal epithelial membrane permeability of the major compounds of $C$. genistoides when present in the semi-purified fractions, XEF and BEF. A bidirectional intestinal permeability assay was used for determining efflux characteristics ex vivo [15]. Additionally, we aimed to delineate the reaction kinetic behavior of the target compounds during accelerated storage of the extract and fractions to gain insight into their relative shelf-life stability.

\section{Results and Discussion}

Low systemic bioavailability of dietary polyphenols underpins their potential as intestinal enzyme inhibitors, as their confinement to the GIT lumen due to weak membrane permeability places them at the intended site of action [16]. Intestinal membrane permeability and aqueous solubility of compounds form the basis of the Biopharmaceutics Classification System, which allows broad predictions of the rate-limiting step in their intestinal absorption following oral administration [17]. Transport across excised porcine intestinal tissue was used to assess the potential of xanthones and benzophenones of $C$. genistoides ( $\nabla$ Fig. 1 ) to target $\alpha$-glucosidase in the lumen of the GIT.

Bidirectional intestinal epithelial permeability assays were conducted to determine the permeability of each target compound both as a constituent of its parent fraction $\left(\mathrm{XEF}_{0}\right.$ or $\left.\mathrm{BEF}_{0}\right)$ or as a constituent of its parent fraction tested in combination with the other fraction. The mangiferin and isomangiferin content of $\mathrm{XEF}_{0}$ were 37.1 and $11.1 \%$, respectively, whereas the IDG, I3G, and M3G content of $\mathrm{BEF}_{0}$ were $7.0,5.2$, and $4.1 \%$, respectively.

Use of the Sweetana-Grass diffusion apparatus required mounting of freshly excised porcine intestinal tissue sections ( $<20$ min post-slaughter). Tissue integrity was maintained as indicated by low transport of Lucifer yellow $(<5 \%)$ [18] and a TEER value $>30 \Omega \cdot \mathrm{cm}^{2}$, considered acceptable for excised small intestinal tissue [19] over the experimental period (Table 1S, Supporting Information).

The apparent permeability coefficient $\left(P_{\text {app }}\right)$, defined as the initial flux of a compound across a membrane, normalized by the membrane surface area and donor compartment concentration, is commonly used for general screening purposes in in vitro or ex vivo intestinal permeability studies [20]. The ER, representing the ratio of the $P_{a p p}$ value for the secretory (B-A) direction vs. the absorptive (A-B) direction, is indicative of the degree of efflux of a 
<smiles>[R2]c1c(O)c([R2])c2oc3cc(O)c(O)cc3c(=O)c2c1O</smiles>

Xanthones

Mangiferin: $\mathrm{R}_{1}=\mathrm{H}, \mathrm{R}_{2}=\beta$-D-glucopyranosyl

Isomangiferin: $\mathrm{R}_{1}=\beta$-D-glucopyranosyl, $\mathrm{R}_{2}=\mathrm{H}$<smiles>[R]Oc1cc(O)c(C(=O)c2ccc(O)c([R3])c2)c(O)c1[R2]</smiles>

Benzophenones

I3G: $\mathrm{R}_{1}=\mathrm{H}, \mathrm{R}_{2}=\beta$-D-glucopyranosyl; $\mathrm{R}_{3}=\mathrm{H}$

IDG: $\mathrm{R}_{1}=\beta$-D-glucopyranosyl, $\mathrm{R}_{2}=\beta$-D-glucopyranosyl; $\mathrm{R}_{3}=\mathrm{H}$

M3G: $\mathrm{R}_{1}=\mathrm{H}, \mathrm{R}_{2}=\beta$-D-glucopyranosyl; $\mathrm{R}_{3}=\mathrm{OH}$

- Fig. 1 Structures of major xanthones and benzophenones found in honeybush (Cyclopia genistoides Vent.). I3G, 3- $\beta$-D-glucopyranosyliriflophenone; IDG, 3- $\beta$-D-glucopyranosyl-4-O- $\beta$-D-glucopyranosyliriflophenone; M3G, 3- $\beta$-D-glucopyranosylmaclurin.

- Table 1 Apparent permeability coefficients and efflux ratios for the 2 major xanthones, mangiferin and isomangiferin, and the 2 major benzophenones, IDG and I3G, in Cyclopia genistoides fractions, tested individually or in combination, for ex vivo intestinal permeability.

\begin{tabular}{|c|c|c|c|c|c|c|}
\hline \multirow[t]{2}{*}{ Compound } & \multicolumn{3}{|c|}{ Single fractions ( $\mathrm{XEF}_{0}$ or $\mathrm{BEF}_{0}$ individually) } & \multicolumn{3}{|c|}{ Combined fractions $\left(1 \mathrm{XEF}_{0}: 1 \mathrm{BEF}_{0}\right)$} \\
\hline & $P_{\mathrm{app}}^{\mathrm{AB}}\left(\times 10^{-7} \mathrm{~cm} / \mathrm{s}\right)$ & $P_{\mathrm{app}}^{\mathrm{BA}}\left(\times 10^{-7} \mathrm{~cm} / \mathrm{s}\right)$ & Efflux ratio & $P_{\mathrm{app}}^{\mathrm{AB}}\left(\times 10^{-7} \mathrm{~cm} / \mathrm{s}\right)$ & $P_{\mathrm{app}}^{\mathrm{BA}}\left(\times 10^{-7} \mathrm{~cm} / \mathrm{s}\right)$ & Efflux ratio \\
\hline IDG & $1.29 \pm 0.1$ & $3.93 \pm 0.1$ & 3.05 & $0.96 \pm 0.3$ & $2.05 \pm 1.3$ & 2.14 \\
\hline I3G & nd & $10.1 \pm 1.6$ & - & - & traces & - \\
\hline Mangiferin & $0.93 \pm 0.3$ & $1.60 \pm 0.1$ & 1.71 & $1.43 \pm 0.1$ & $2.41 \pm 0.5$ & 1.68 \\
\hline Isomangiferin & $1.06 \pm 0.4$ & $1.91 \pm 0.1$ & 1.81 & $1.78 \pm 0.2$ & $2.73 \pm 0.7$ & 1.53 \\
\hline Rhodamine 123 & $1.38 \pm 0.4$ & $4.12 \pm 1.8$ & 2.99 & - & - & - \\
\hline
\end{tabular}

given compound (i.e., $E R=1$ indicates that no efflux occurred, $E R$ $>2$ suggests active efflux mechanisms are involved, and $1<E R<2$ suggests that passive permeation mechanisms dominate [21].

For transport in the absorptive (A-B) direction, I3G was not detected in the acceptor compartment over the experimental period, precluding calculation of $P_{\mathrm{app}}^{\mathrm{AB}}$ and ER values for this compound when tested as a constituent of $\mathrm{BEF}_{0}$ ( $\triangleright$ Table 1$)$. Calculation of $P_{\text {app }}$ was also not possible for $13 \mathrm{G}$ when present in the combined fractions because of low transport rates across the membrane in either direction. Although this cannot provide further insight into the extent of efflux of I3G, it does indicate that I3G is unlikely to be absorbed to a great degree by enterocytes into the blood circulation. ER values for mangiferin and isomangiferin were between 1 and 2 (1.53-1.81), whereas for IDG ER = 3.05 was similar to that of Rhodamine 123 (ER = 2.99), a known substrate for the intestinal glycoprotein efflux transporter, P-glycoprotein 1 (P-gp) [22]. Various dietary flavonoids induce the P-gp expression by enterocytes in vitro and in vivo, an adaptation thought to serve as a defense mechanism against the entry of lipophilic xenobiotics into the organism [23]. Mangiferin has been confirmed as a P-gp substrate in a Caco-2 cell study [24]; mangiferin, isomangiferin, IDG, and I3G, as constituents of $C$. genistoides extract, upregulated the P-gp efflux drug transporter encoded by the $A B C B 1$ gene in $C 3 A$ liver cells, treated at concentrations up to $250 \mu \mathrm{g} / \mathrm{mL}$ (i.e., $0.4-$ $0.6 \mathrm{mM}$ ) [25]. However, such cell models cannot mimic additional factors (e.g., mucus layer secretions and tight junctions) that come into play in vivo [26]. The ex vivo assay system employed in the present study more closely mirrors physiological conditions.

Further context in terms of the present results and previous cell-based studies is the confirmed low oral bioavailability and tissue disposition of many dietary polyphenols (i.e., their tendency to not reach target tissues at the required concentrations following interaction with microbiota, absorption, and phase II metabolism) [27]. For example, oral bioavailability of mangiferin in normal and alloxan-induced diabetic rats amounted to just $1.71 \%$ and $0.80 \%$, respectively [28], while the peak plasma concentra- 
tions reached after oral administration of $400 \mathrm{mg} / \mathrm{kg}$ mangiferin to normal and streptozotocin-induced diabetic rats were $715.04 \pm 600.14 \mathrm{ng} / \mathrm{mL}$ and $1995.52 \pm 408.97 \mathrm{ng} / \mathrm{mL}$, respectively [29]. Although in vivo studies are ideal, evidence of in vitro modulation of P-gp in cell-based models is useful, as it emphasizes the likelihood of in vivo efflux of dietary polyphenols by cells expressing the P-gp transporter in high amounts, such as small intestinal enterocytes [23].

Additional to the dominance of efflux mechanisms in the transport of the target compounds, an examination of their structural features may also provide insight. Not only is the violation of 2 or more of Lipinski's "rule of 5" criteria predicted to lead to poor oral bioavailability of a compound [30], as indicated for the target compounds (Table 2S, Supporting Information), but Seelig [31] noted that binding to P-gp increases with the strength and number of electron donor or hydrogen bond acceptor groups. The higher ER of IDG compared with those of the xanthones could be related to its additional glucose moiety, resulting in a molar mass $>500 \mathrm{~g} / \mathrm{mol}$, larger polar surface area, and greater number of hydrogen bond acceptor groups and "rule of 5 " violations (3), suggesting its stronger affinity to P-gp. I3G with lower membrane permeability than the xanthones ( $\vee$ Table 1 ) has the same number of hydrogen bond donors than the 2 xanthones (i.e., 8), but 1 less hydrogen bond acceptor (10 vs. 11) and 2 more rotatable bonds (4 vs. 2).

Although the "rule of 5" can give an indication of oral bioavailability based on molecular features, it does not account for other factors (e.g., the presence of other constituents in a multi-compound extract or the in vivo gastrointestinal environment). Moreover, some authors have diverged in their interpretation of the "rule of 5", (e.g., 2 widely cited review articles have claimed that the molecular structure of mangiferin fulfills the Lipinski criteria that predict good oral bioavailability [32,33], despite overwhelming evidence to the contrary reported elsewhere) [8-12, 28, 29]. Data such as those reported in the present study add to the body of evidence that confirms low oral bioavailability, related to P-gp and/or passive efflux mechanisms, and supports the notion of focusing on an intestinal target.

Evidence from other studies, one using Caco-2 cells [34] and another in rats [13], indicated that mangiferin showed higher intestinal permeability as part of a plant extract than as a pure standard, suggesting that its absorption could be enhanced by other extract constituents. Mortimer [11], measuring the transport of mangiferin, isomangiferin, and I3G present in a methanolic extract of $C$. subternata $(1.9,0.6$, and $0.7 \%$, respectively) across porcine intestine using a flow-through diffusion system, showed concentration-dependent diffusion of the compounds across the small intestine. I3G had a slightly higher $P_{\mathrm{app}}^{\mathrm{AB}}$ value than mangiferin and isomangiferin, different from the results of the present study. Previously, Raaths [12] showed ER values $>1$ across porcine small intestinal section, not only for IDG, mangiferin, and isomangiferin but also for I3G. The compounds were present in a crude, nonultrafiltered extract of $C$. genistoides and its fractions. The extract from which $\mathrm{XEF}_{0}$ and $\mathrm{BEF}_{0}$ were prepared for the present study was ultrafiltered through a $10 \mathrm{kDa}$ regenerated cellulose membrane, which removed large molecules and changed extract composition [35]. The modulatory effects of dietary amino acids, polyphenols, and various natural extracts on intestinal tight junctions have been described elsewhere [36,37]. Glucose and sodium, when present as food additives, are also known to enhance intestinal permeability [38]. As the extracts and fractions of C. genistoides are not fully characterized at this stage, such modulatory effects on absorption, due to matrix effects, cannot be ruled out.

The results of our study confirmed the validity of developing an antidiabetic nutraceutical containing $C$. genistoides xanthones and benzophenones, aimed at the inhibition of intestinal AG. Low transport rates across the epithelial membrane, coupled with efflux mechanisms (likely mediated by P-gp transporters), would effectively concentrate the compounds at the intended site of action (GIT lumen).

The moisture sorption characteristics of dried plant extracts, intended for commercialization as functional products or ingredients, is important when selecting suitable packaging material and specifying storage and handling conditions. Uptake of moisture by hygroscopic products would accelerate physical and chemical changes as shown for a spray-dried Cyclopia subternata extract that deliquesces at $>25^{\circ} \mathrm{C}$ and $>55 \% \mathrm{RH}$ ) [14]. In the present study, M3G was the most labile of the compounds investigated and showed greater stability in $\mathrm{UCGE}_{0}$ than in $\mathrm{BEF}_{0}(\triangleright \mathrm{Ta}$ ble 2), indicating that composition of the ultrafiltered extract (prefractionation) may provide a degree of protection against chemical degradation. The rate of moisture uptake was rapid during the first $18 \mathrm{~h}$ of storage $\left(\mathrm{BEF}_{0}>\mathrm{UCGE_{0 }}>\mathrm{XEF}_{0}\right.$; > Fig. 2), thereafter approaching steady state. After $96 \mathrm{~h}$, the mass increases of $\mathrm{BEF}_{0}, \mathrm{UCGE}_{0}$, and $X \mathrm{XF}_{0}$ were $22.7,14.0$, and $10.7 \%$, respectively, with visible liquefaction of $\mathrm{UCGE}_{0}$ and $\mathrm{BEF}_{0}$ while $\mathrm{XEF}_{0}$ retained the superficial appearance of a dry product (Fig. 2S, Supporting Information).

Moisture sorption analysis of freeze-dried samples at $25^{\circ} \mathrm{C}$ confirmed that $\mathrm{BEF}_{0}$ was substantially more hygroscopic than $\mathrm{XEF}_{0}$, with mass increases of $72.5 \%$ and $21.3 \%$, respectively, measured at $97 \%$ RH ( $\triangleright$ Fig. 3). Also included in the moisture sorption analysis was $\mathrm{D}$-pinitol, which is present in substantial quantities in $\mathrm{UCGE}_{0}(6.1 \%)$ and $\mathrm{BEF}_{0}$ (8.2\%), compared to $\mathrm{XEF}_{0}$ (0.3\%) (Page 6, Supporting Information). It showed a sharp increase in mass (90.9\%) due to moisture uptake at $\mathrm{RH}>75 \%$, a clear indication that its presence in these samples contributed to their moisture uptake. $\mathrm{BEF}_{0}$ was produced by desorbing a $\mathrm{UCGE}_{0}$-loaded resin column with dilute aqueous solutions of ethanol (5-10\% v/v). Therefore, it could be expected that the majority of hydrophilic constituents in $\mathrm{UCGE}_{0}$ would have desorbed along with the target benzophenones in $\mathrm{BEF}_{0}$. In addition to D-pinitol, $\mathrm{BEF}_{0}$ contained $1.6 \% \mathrm{D}$-glucose, which was not detected in $\mathrm{XEF}_{0}$. The greater degree of moisture uptake in $\mathrm{BEF}_{0}$ could also be related to the additional glucosyl moiety of IDG, its major benzophenone $(7.04 \% \mathrm{w} /$ w), which was not present in $\mathrm{XEF}_{0}$. UCGE $\mathrm{UCH}_{0}$ and $\mathrm{XEF}_{0}$ can be classified as "hygroscopic" and $\mathrm{BEF}_{0}$ as "very hygroscopic" [39].

According to International Conference on Harmonisation (ICH) guidelines, a decrease in the concentration of bioactive compound $>5 \%$ during accelerated stability testing is considered a "significant change" [40]. Given the rapid increase in moisture content of $\mathrm{UCGE}_{0}, \mathrm{XEF}_{0}$, and $\mathrm{BEF}_{0}$, accompanied by target compound degradation at $40^{\circ} \mathrm{C} / 75 \% \mathrm{RH}$ ( $\bullet$ Fig. 2), further investiga- 
- Table 2 Change in target compound content of ultrafiltered Cyclopia genistoides extract and its xanthone- and benzophenone-enriched fractions after $96 \mathrm{~h}$ of storage with mini-hygrostat $\left(40^{\circ} \mathrm{C} / 75 \% \mathrm{RH}\right)$.

\begin{tabular}{|c|c|c|c|c|c|c|c|c|c|}
\hline \multirow[t]{2}{*}{ Compound } & \multicolumn{3}{|l|}{$\mathrm{UCGE}_{0}{ }^{\mathrm{a}}$} & \multicolumn{3}{|l|}{$\mathrm{XEF}_{0}{ }^{\mathrm{b}}$} & \multicolumn{3}{|l|}{$\mathrm{BEF}_{0}{ }^{\mathrm{c}}$} \\
\hline & Initiald $^{\mathbf{d}}$ & $96 \mathrm{~h}^{\mathrm{e}}$ & $\Delta(\%)^{f}$ & Initial & $96 \mathrm{~h}$ & $\Delta(\%)$ & Initial & $96 \mathrm{~h}$ & $\Delta(\%)$ \\
\hline MGFg & $11.80 \pm 0.08$ & $11.51 \pm 0.34$ & -2.8 & $37.05 \pm 0.24$ & $36.86 \pm 0.30$ & -0.5 & - & - & - \\
\hline IMGFh & $3.36 \pm 0.02$ & $3.32 \pm 0.10$ & -1.1 & $11.06 \pm 0.07$ & $10.55 \pm 0.18$ & -4.5 & - & - & - \\
\hline $\mathrm{IDG}^{\mathrm{i}}$ & $1.18 \pm 0.01$ & $1.12 \pm 0.03$ & -4.8 & - & - & - & $7.04 \pm 0.02$ & $6.99 \pm 0.09$ & -0.7 \\
\hline M3Gj & $0.55 \pm 0.01$ & $0.50 \pm 0.01$ & -9.5 & - & - & - & $4.07 \pm 0.07$ & $3.44 \pm 0.13$ & -15.4 \\
\hline $13 G^{k}$ & $1.48 \pm 0.00$ & $1.35 \pm 0.03$ & -8.8 & $3.33 \pm 0.03$ & $3.11 \pm 0.02$ & -6.5 & $5.22 \pm 0.13$ & $4.74 \pm 0.05$ & -9.2 \\
\hline
\end{tabular}

a ultrafiltered Cyclopia genistoides extract; ${ }^{b}$ xanthone-enriched fraction; ' benzophenone-enriched fraction; ${ }^{\mathrm{d}}$ initial content (g/100 g d. b.) and ${ }^{\mathrm{e}}$ content (g/100 g d. b.after 96 hours; ${ }^{f}$ percentage change in content after $96 \mathrm{~h} ;{ }^{9}$ mangiferin; ${ }^{\mathrm{h}}$ isomangiferin; ${ }^{i}$ - $\beta$-D-glucopyranosyl-4-O- $\beta$-D-glucopyranosyliriflophenone; $\mathrm{j}$ 3- $\beta$-D-glucopyranosylmaclurin; ${ }^{k} 3$ - $\beta$-D-glucopyranosyliriflophenone. Compound content values are presented as mean \pm standard deviation $(n=3)$

tion of their chemical stability was merited in the absence of high $\mathrm{RH}$ by placing the samples in moisture-impermeable containers. For countries with a subtropic/Mediterranean climate such as South Africa, the $\mathrm{ICH}$ recommends $40^{\circ} \mathrm{C} / 75 \% \mathrm{RH}$ for accelerated (6 months) storage testing [41]. An abbreviated storage period of 12 wk was employed, and the moisture-impermeable container mimicked the type of packaging proposed for storage and distribution. Sample mass did not increase during storage, confirming that compound degradation would be the result of temperature and not due to moisture uptake.

The first order reaction model was selected to model compound degradation ( $\vee$ Table 3 ) and to fit the data for calculation of degradation rate constants $(k)(\triangleright$ Fig. 4 ) in accordance with other studies on the thermal degradation kinetics of the xanthones and benzophenones of $C$. genistoides [42,43]. The relatively low percentage of xanthone degradation (13.35-15.59\%) resulted in a weaker fit of the data to the various models $\left(0.531<R_{\text {adj }}^{2}<0.791\right) \quad$ compared with the benzophenones $\left(0.633<R_{\text {adj }}^{2}<0.894\right)$. M3G was again most susceptible to degradation over the 12-wk storage period, while IDG was the most stable compound (degradation $<13 \%$ ) and subsequently not fitted to the kinetic models. The first order degradation rate constants (k) and percentage degradation at $6 \mathrm{wk}$ and $12 \mathrm{wk}$ of storage are presented in - Table 4 . The highest $k$-values were observed for the most heat-labile compound, M3G, which degraded at a higher rate in $\mathrm{BEF}_{0}(k=0.0503)$ than $\mathrm{UCGE}_{0}(k=0.0347)$. The relative chemical stability of the compounds was similar to that observed in an aqueous model solution ( $\mathrm{pH} 5$ ) (i.e., M3G < mangiferin < I3G $<$ isomangiferin < IDG) [42] and in C. genistoides plant material during high-temperature oxidation, an essential step in the production of "fermented" honeybush tea [43].

In conclusion, poor intestinal membrane permeation of the major bioactive xanthones and benzophenones of $C$. genistoides confirmed their suitability for further investigation as potential intestinal $\alpha$-glucosidase inhibitors. The hygroscopicity of the dried C. genistoides extract and fractions, particularly $\mathrm{BEF}_{0}$, and the susceptibility of some of the target compounds to degrade at $40^{\circ} \mathrm{C}$ accelerated by humid environmental conditions (75\% RH) emphasize the need to provide adequate barrier packaging to protect the active compounds. These findings serve as proof of concept toward the development of an efficacious antidiabetic nutraceutical product derived from C. genistoides.

\section{Materials and Methods}

\section{Chemicals and reagents}

Rhodamine 123, Krebs-Ringer bicarbonate (KRB) buffer, and DMSO were purchased from Sigma-Aldrich. Authentic phenolic standards (purity > 95\%) were obtained from Sigma-Aldrich (mangiferin; D-pinitol), Phytolab (I3G; isomangiferin), or isolated (IDG and M3G) from C. genistoides [5]. All other reagents were of analytical grade and supplied by Sigma-Aldrich or Merck.

\section{Extract and fractions}

Ultrafiltered Cyclopia genistoides extract (UCGE $)$ (retention sample code: ARC 2038P) and triplicate XEFs and BEFs (A to C) were produced as described [7]. $\mathrm{XEF}_{0}$ was obtained by combining an equal mass of XEF $A, B$, and $C$, while $B E_{0}$ was obtained by combining an equal mass BEF $A, B$, and $C$ (retention samples coded as ARC2038-XEF A, etc.).

\section{Ex vivo intestinal permeability}

Viable porcine jejenum tissue, obtained from the abattoir, was prepared for intestinal permeability assays along with KRB buffer, adjusted to $\mathrm{pH} 7.4$ using $2 \mathrm{M} \mathrm{NaOH}$, as previously described [22]. The 2 fractions $\left(\mathrm{XEF}_{0}, \mathrm{BEF}_{0}\right)$ and a $1: 1 \mathrm{XEF}_{0}: \mathrm{BEF}_{0}$ combination were dissolved in KRB buffer $(1.71 \mathrm{mg} / \mathrm{mL})$ and the temperature equilibrated at $37^{\circ} \mathrm{C}$ prior to the transport experiment.

Intestinal tissue sections were mounted on the half-cells of a Sweetana-Grass diffusion apparatus (Fig. 1S, Supporting Information), with the mucosal side facing the apical chamber (transport surface area $=1.78 \mathrm{~cm}^{2}$ ). The half-cells were clamped together to form diffusion chambers that were inserted in the apparatus, maintained at $37^{\circ} \mathrm{C}$. KRB buffer $(7 \mathrm{~mL})$ at $37^{\circ} \mathrm{C}$ was added to each half-cell compartment, followed by continuous bubbling of a carbogen gas mixture $\left(95 \% \mathrm{O}_{2}: 5 \% \mathrm{CO}_{2}\right)$ through the buffer in each half-cell. The buffer was incubated for $15 \mathrm{~min}$ to accustom 

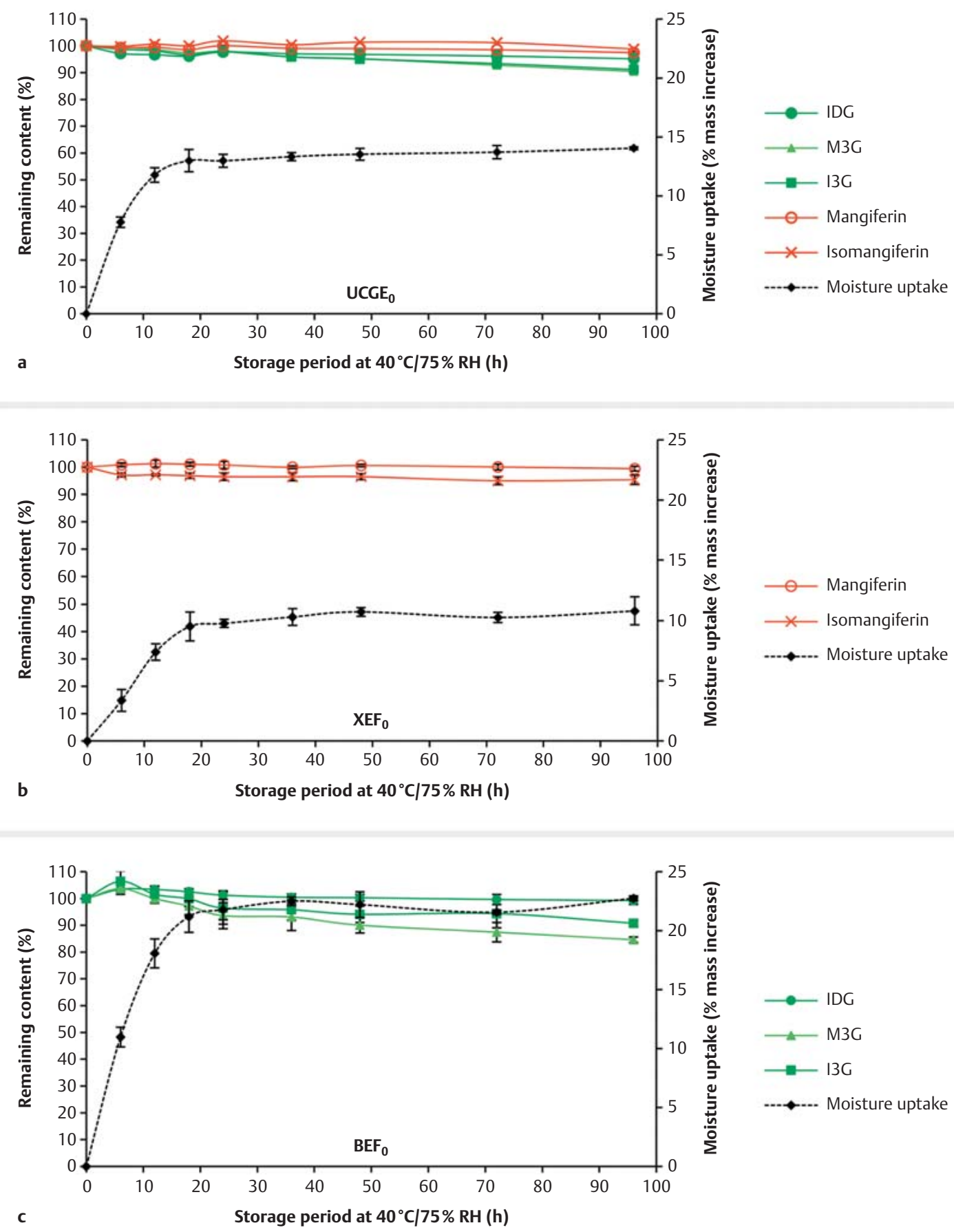

- Fig. 2 Remaining content of the target compounds (\%) and degree of moisture uptake (expressed as \% mass increase) in freeze-dried (a) ultrafiltered Cyclopia genistoides extract (UCGE $)$, (b) xanthone-enriched fraction $\left(\mathrm{XEF}_{0}\right)$, and (c) benzophenone-enriched fraction $\left(\mathrm{BEF}_{0}\right)$ as a function of time during storage at $40^{\circ} \mathrm{C} / 75 \% \mathrm{RH}$ for $96 \mathrm{~h}$ in sealed glass vials containing saturated $\mathrm{NaCl}$ mini-hygrostats. (I3G = 3- $\beta$-D-glucopyranosyliriflophenone; IDG = 3- $\beta$-D-glucopyranosyl-4-O- $\beta$-D-glucopyranosyliriflophenone; M3G = 3- $\beta$-D-glucopyranosylmaclurin). Values are presented as mean \pm standard deviation $(n=3)$.

the tissue to the experimental conditions whereafter the contents of all compartments were aspirated to remove the buffer. Transport in the absorptive (apical-to-basolateral, A-B) direction was investigated by adding $7 \mathrm{~mL} \mathrm{KRB}$ buffer $\left(37^{\circ} \mathrm{C}\right)$ to the basolateral (serosal) compartment, and an equal volume of the test solution to the apical (mucosal) compartment at 0 min. Transport in the secretory direction (basolateral-to-apical, B-A) was investigated by adding $7 \mathrm{~mL} \mathrm{KRB}$ buffer $\left(37^{\circ} \mathrm{C}\right)$ to the apical compartment, 


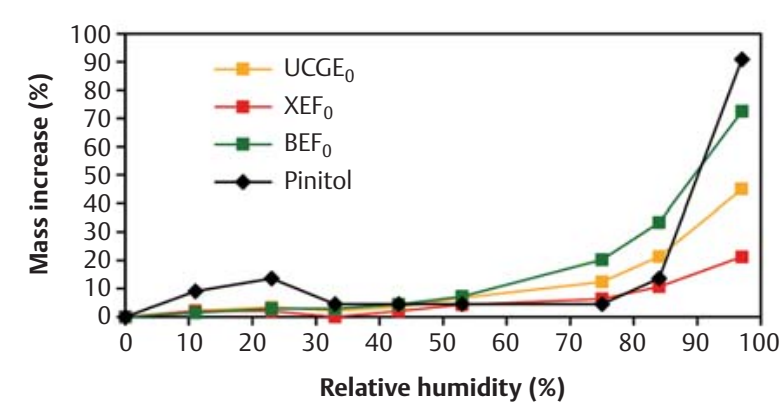

- Fig. 3 Increase in mass of freeze-dried ultrafiltered Cyclopia genistoides extract $\left(\mathrm{UCGE}_{0}\right)$, xanthone-enriched fraction $\left(\mathrm{XEF}_{0}\right)$, benzophenone-enriched fraction $\left(\mathrm{BEF}_{0}\right)$, and $\mathrm{D}$-pinitol due to moisture absorption as a function of relative humidity at $25^{\circ} \mathrm{C}$.

and an equal volume of the test solution to the basolateral compartment at $0 \mathrm{~min}$. The tissue was exposed to the test solution for $2 \mathrm{~h}$, during which samples $(500 \mu \mathrm{L})$ were collected from the acceptor compartment at 20-min intervals and replaced with an equal volume of KRB buffer $\left(37^{\circ} \mathrm{C}\right)$ [22]. All samples were freezedried and stored at $-18^{\circ} \mathrm{C}$ until quantification of the target compounds by HPLC-DAD. All the transport studies were carried out in triplicate.

The apparent permeability coefficient $(\mathrm{cm} / \mathrm{s})\left(P_{a p p}\right)$ for each target compound was calculated using Eq. 1 [21]:

$P_{\mathrm{app}}=\left(\frac{d Q}{d t}\right) \times\left(\frac{1}{60 A C_{0}}\right)$

where $d Q / d t$ is the permeability rate (slope of \% transport/min curve), $A$ is the transport surface area $\left(\mathrm{cm}^{2}\right)$, and $C_{0}$ is the initial compound concentration on the donor side.
The ER is an index of intestinal permeability that compares the adsorptive and secretory permeability [44] and is represented by Eq. 2:

$\mathrm{ER}=\frac{P_{\mathrm{app}}^{\mathrm{BA}}}{P_{\mathrm{app}}^{\mathrm{AB}}}$

where $P_{\mathrm{app}}^{\mathrm{BA}}$ and $P_{\mathrm{app}}^{\mathrm{AB}}$ represent $P_{\text {app }}$ values in the basolateral-to-apical (B-A) and apical-to-basolateral (A-B) directions, respectively.

Rhodamine 123 , a fluorescence marker and substrate of the P-gp efflux transporter [22], served as the model compound for the bidirectional transport studies. It was dissolved in KRB buffer to a final concentration of $5 \mathrm{mM}$. The samples collected during the bidirectional transport study (in triplicate in both the A-B and B-A directions) were analyzed for rhodamine 123 content using a validated fluorescence spectroscopy assay $\left(\lambda_{\mathrm{Ex}}=480 \mathrm{~nm} ; \lambda_{\mathrm{Em}}=\right.$ $520 \mathrm{~nm}$ ) [22] and a Spectramax Paradigm ${ }^{\circledR}$ multi-mode detection platform plate reader (Molecular Devices, LLC).

Lucifer yellow was included as an exclusion marker to indicate excised tissue integrity over the experimental time period [18]. The lucifer yellow transport study was carried out only in the A-B direction and the lucifer yellow concentration in the samples quantified by fluorescence spectroscopy assay $\left(\lambda_{\mathrm{Ex}}=485 \mathrm{~nm}\right.$; $\lambda_{\mathrm{Em}}=535 \mathrm{~nm}$ ) [45]. The TEER was measured using an ECA 825A Dual Channel Epithelial Voltage Clamp (Warner Instruments) at the start of the experiment with addition of the sample and at the end of the $2 \mathrm{~h}$ sampling period.

\section{Storage stability}

Stability testing of target compounds in $\mathrm{XEF}_{0}$ and $\mathrm{BEF}_{0}$, as well as the original extract $\left(\mathrm{UCGE}_{0}\right)$, was performed in triplicate under accelerated storage conditions $\left(40^{\circ} \mathrm{C} / 75 \%\right.$ relative humidity, $\left.\mathrm{RH}\right)$ over a period of $96 \mathrm{~h}$. Mini-hygrostats, containing a saturated $\mathrm{NaCl}$ solution and constructed as described by Human et al. [46], were loaded with ca. $30 \mathrm{mg}$ freeze-dried sample (accurately weighed to 5-decimals), sealed, placed in a darkened stability cabinet at $40^{\circ} \mathrm{C}$

- Table 3 Adjusted coefficient of determination $\left(R_{\text {adj }}^{2}\right)$ between mean observed content and predicted contents for the major Cyclopia genistoides compounds in $\mathrm{UCGE}_{0}, \mathrm{XEF}_{0}$, and $\mathrm{BEF}_{0}$.

\begin{tabular}{|c|c|c|c|c|c|}
\hline \multirow[t]{2}{*}{ Compound } & \multirow[t]{2}{*}{ Stored sample } & \multicolumn{4}{|c|}{ Adjusted coefficient of determination $\left(R_{\mathrm{adj}}^{2}\right)$} \\
\hline & & Zero order ${ }^{a}$ & First order $^{b}$ & Second order ${ }^{c}$ & Fractional conversion ${ }^{d}$ \\
\hline \multirow[t]{2}{*}{ Mangiferin } & $\mathrm{UCGE}_{0} \mathrm{e}^{\mathrm{e}}$ & 0.676 & 0.678 & 0.680 & 0.668 \\
\hline & $\mathrm{XEF}_{0}^{\mathrm{f}}$ & 0.531 & 0.538 & 0.544 & 0.747 \\
\hline \multirow[t]{2}{*}{ Isomangiferin } & $\mathrm{UCGE}_{0}$ & 0.722 & 0.725 & 0.727 & 0.716 \\
\hline & $\mathrm{XEF}_{0}$ & 0.749 & 0.757 & 0.765 & 0.791 \\
\hline \multirow[t]{2}{*}{$13 \mathrm{G}^{9}$} & $\mathrm{UCGE}_{0}$ & 0.824 & 0.833 & 0.835 & 0.829 \\
\hline & $\mathrm{BEF}_{0}{ }^{\mathrm{h}}$ & 0.633 & 0.663 & 0.691 & 0.774 \\
\hline \multirow[t]{2}{*}{$M 3 G^{i}$} & $\mathrm{UCGE}_{0}$ & 0.816 & 0.815 & 0.808 & 0.808 \\
\hline & $\mathrm{BEF}_{0}$ & 0.818 & 0.854 & 0.882 & 0.894 \\
\hline
\end{tabular}

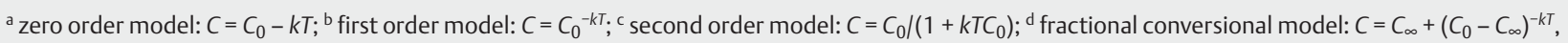
where $C_{0}$ is the initial content $\left(\mathrm{g} / 100 \mathrm{~g}\right.$ sample, d. b.), $T$ is the time in $w k, k$ is the reaction rate constant $\left(w^{-1}\right)$, and $C_{\infty}$ is the stable fraction of the compound (g/100 g sample, d. b.); ${ }^{e}$ ultrafiltered Cyclopia genistoides extract used as starting material for production of fractions; ${ }^{f}$ xanthone-enriched fraction; ${ }^{9} 3-\beta$-Dglucopyranosyliriflophenone; ${ }^{\mathrm{h}}$ benzophenone-enriched fraction; ${ }^{\mathrm{i}}$ 3- $\beta$-D-glucopyranosylmaclurin 

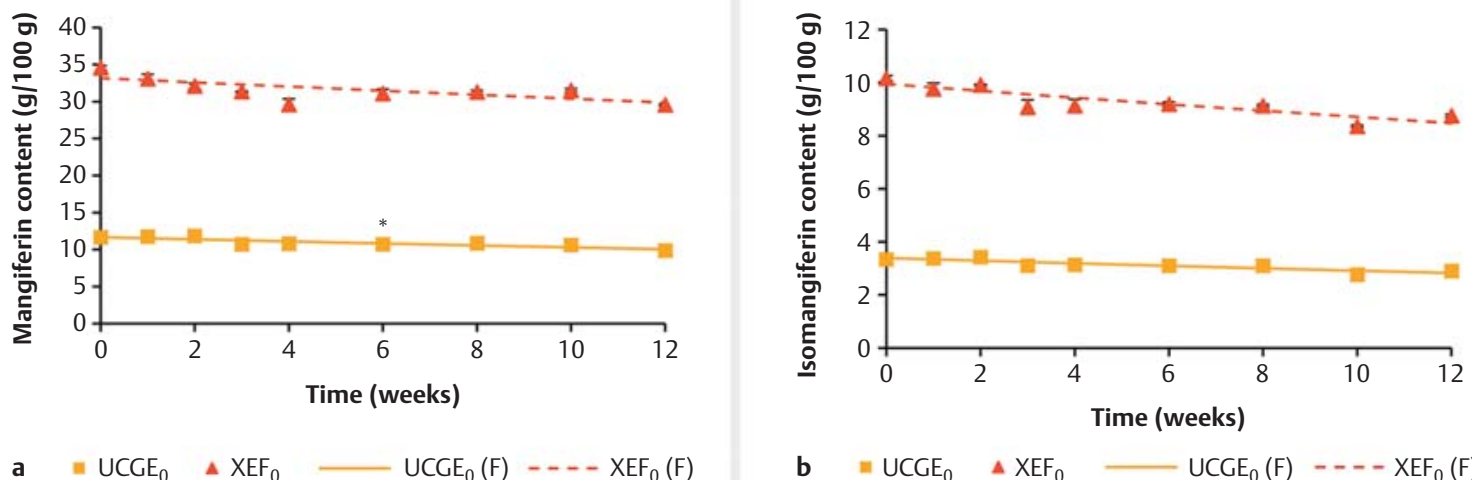

a $=\mathrm{UCGE}_{0} \Delta \mathrm{XEF}_{0} \longrightarrow \mathrm{UCGE}_{0}(\mathrm{~F}) \ldots-\mathrm{XEF}_{0}(\mathrm{~F})$

b $=\mathrm{UCGE}_{0} \quad \Delta \mathrm{XEF}_{0} \longrightarrow \mathrm{UCGE}_{0}(\mathrm{~F})----\mathrm{XEF}_{0}(\mathrm{~F})$
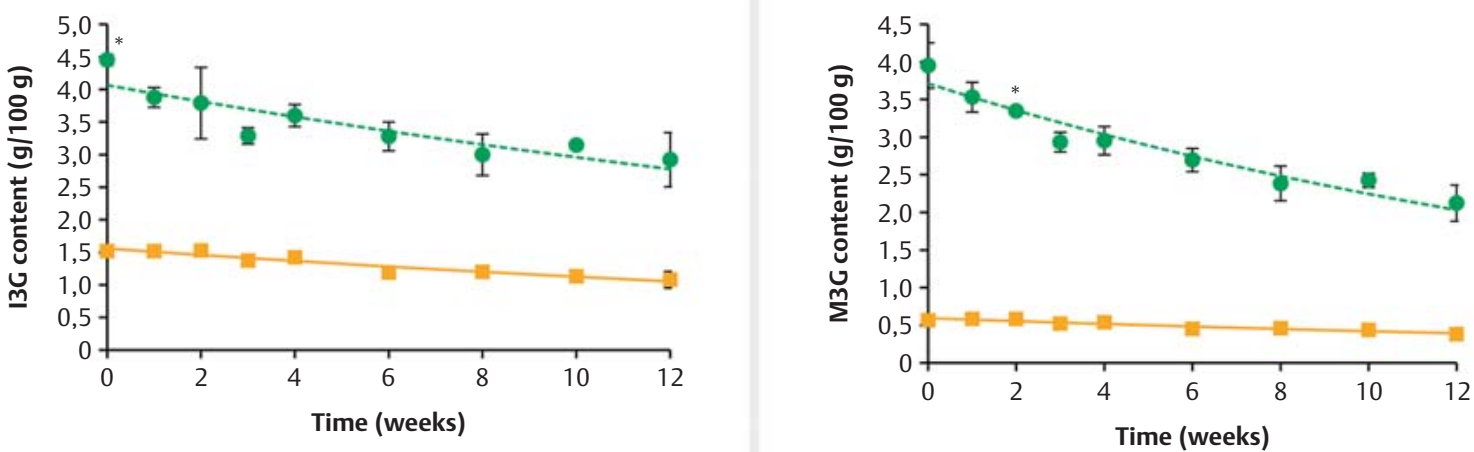

c

$$
=\mathrm{UCGE}_{0} \bullet \mathrm{BEF}_{0}
$$

$\mathrm{UCGE}_{0}(\mathrm{~F})$

- $\mathrm{BEF}_{0}(\mathrm{~F})$

d $=\mathrm{UCGE}_{0} \quad \bullet \mathrm{BEF}_{0} \longrightarrow \mathrm{UCGE}_{0}(\mathrm{~F}) \quad \cdots \mathrm{BEF}_{0}(\mathrm{~F})$

- Fig. 4 First order model predicted values (indicated by [F], solid and broken lines) and experimental data (markers only) for degradation of (a) mangiferin, (b) isomangiferin, (c) 3- $\beta$-D-glucopyranosyliriflophenone (I3G), and (d) 3- $\beta$-D-glucopyranosylmaclurin (M3G) in different freeze-dried samples ( $\mathrm{UCGE}_{0}$, ultrafiltered Cyclopia genistoides extract; $\mathrm{XEF}_{0}$, xanthone-enriched fraction; $\mathrm{BEF}_{0}$, benzophenone-enriched fraction) as a function of time during storage at $40^{\circ} \mathrm{C} / 75 \%$ relative humidity for $12 \mathrm{wk}$ in moisture-impermeable amber glass vials. Values are presented as mean \pm standard deviation ( $n=3$, except $* n=2$, outlier removed).

- Table 4 Degradation (\%) and first order ${ }^{\mathrm{a}}$ degradation rate constants ( $k$ ) for Cyclopia genistoides xanthones in powdered samples stored at $40^{\circ} \mathrm{C}$ in moisture-impermeable amber glass vials.

\begin{tabular}{|c|c|c|c|c|c|c|}
\hline \multirow{3}{*}{$\begin{array}{l}\text { Stored } \\
\text { sample }\end{array}$} & \multicolumn{6}{|l|}{ Xanthones } \\
\hline & \multicolumn{3}{|l|}{ Mangiferin } & \multicolumn{3}{|l|}{ Isomangiferin } \\
\hline & $\begin{array}{l}\text { Decrease after } \\
6 \mathrm{wk}(\%)\end{array}$ & $\begin{array}{l}\text { Decrease after } \\
12 \mathrm{wk}(\%)\end{array}$ & $k\left(w k^{-1}\right)$ & $\begin{array}{l}\text { Decrease after } \\
6 \text { wk (\%) }\end{array}$ & $\begin{array}{l}\text { Decrease after } \\
12 \text { wk (\%) }\end{array}$ & $k\left(w k^{-1}\right)$ \\
\hline $\mathrm{UCGE}_{0}{ }^{\mathrm{b}}$ & $8.11 \pm 0.9^{*}$ & $15.59 \pm 1.3$ & $0.0125 \pm 0.0017$ & $7.15 \pm 0.1^{*}$ & $13.35 \pm 1.0$ & $0.0153 \pm 0.0019$ \\
\hline $\mathrm{XEF}_{0}{ }^{\mathrm{c}}$ & $10.12 \pm 1.2$ & $14.55 \pm 0.4$ & $0.00872 \pm 0.0016$ & $9.61 \pm 0.8$ & $13.89 \pm 0.5$ & $0.0135 \pm 0.0015$ \\
\hline \multirow{3}{*}{$\begin{array}{l}\text { Stored } \\
\text { sample }\end{array}$} & \multicolumn{6}{|l|}{ Benzophenones } \\
\hline & \multicolumn{3}{|c|}{ 3- $\beta$-D-glucopyranosyliriflophenone (I3G) } & \multicolumn{3}{|c|}{ 3- $\beta$-D-glucopyranosylmaclurin (M3G) } \\
\hline & $\begin{array}{l}\text { Decrease after } \\
6 \mathrm{wk}(\%)\end{array}$ & $\begin{array}{l}\text { Decrease after } \\
12 \mathrm{wk}(\%)\end{array}$ & $k\left(w k^{-1}\right)$ & $\begin{array}{l}\text { Decrease after } \\
6 \text { wk (\%) }\end{array}$ & $\begin{array}{l}\text { Decrease after } \\
12 \mathrm{wk}(\%)\end{array}$ & $k\left(w k^{-1}\right)$ \\
\hline $\mathrm{UCGE}_{0}$ & $21.86 \pm 5.7$ & $28.81 \pm 8.4$ & $0.0326 \pm 0.0029$ & $20.19 \pm 5.7$ & $32.43 \pm 10.5$ & $0.0347 \pm 0.0033$ \\
\hline $\mathrm{BEF}_{0}{ }^{\mathrm{d}}$ & $29.72 \pm 4.7$ & $37.39 \pm 8.9$ & $0.0318 \pm 0.0044$ & $31.79 \pm 3.9$ & $46.28 \pm 6.1$ & $0.0503 \pm 0.0042$ \\
\hline
\end{tabular}


(SMC Scientific Manufacturing), and removed from storage after $6,12,18,24,36,48,72$, and $96 \mathrm{~h}$. The increase in the sample mass due to moisture uptake was determined gravimetrically. After reweighing, $15 \mathrm{~mL}$ aqueous (DMSO) (10\%, v/v) was added to each vial to obtain a solution with a concentration of ca. $2 \mathrm{mg} /$ $\mathrm{mL}$. Aliquots were stored at $-18^{\circ} \mathrm{C}$ until HPLC-DAD analysis.

Stability of the target compounds in $\mathrm{UCGE}_{0}, \mathrm{XEF}_{0}$, and $\mathrm{BEF}_{0}$ was also investigated during a 12-wk storage period under "dry" conditions at $40^{\circ} \mathrm{C}$. Approximately $50 \mathrm{mg}$ of freeze-dried sample was weighed into $24 \mathrm{~mL}$ amber glass vials, sealed with PTFE screw-caps to mimic moisture-impermeable packaging, and placed in a darkened stability cabinet at $40^{\circ} \mathrm{C}$. Samples were removed from the cabinet after 1, 2, 3, 4, 6, 8, 10, and $12 \mathrm{wk}$ of storage. The content of each vial was dissolved in $15 \mathrm{~mL}$ aqueous DMSO $(10 \%, v / v)$, equaling a concentration of ca. $3.3 \mathrm{mg} / \mathrm{mL}$. Aliquots were stored at $-18^{\circ} \mathrm{C}$ until HPLC-DAD analysis.

\section{Moisture sorption analysis}

Moisture sorption analysis was performed on $\mathrm{UCGE}_{0}, \mathrm{XEF}_{0}$, and $\mathrm{BEF}_{0}$ by exposing the freeze-dried samples to 8 different saturated salt solutions, resulting in a step-wise increase in the \% $\mathrm{RH}$ over consecutive days [47]. Saturated salt solutions were prepared by dissolving a known amount of salt (g) (Table 35, Supporting Information) in a known volume of deionized water at room temperature $\left(25^{\circ} \mathrm{C}\right.$ ). Predetermined amounts (ca. 50-100 mg) of each sample were weighed and dried at $40^{\circ} \mathrm{C}$ for $1 \mathrm{~h}$ in a laboratory oven (Labotec) and weighed using a 5-decimal digital balance (Mettler-Toledo International Inc.) to determine the initial dry mass. The samples were placed in a desiccator containing the saturated salt solution, and the mass of each sample was determined after $24 \mathrm{~h}$ of exposure to the atmosphere with known RH. Sample mass was determined until $48 \mathrm{~h}$ elapsed, or until equilibrium in the mass was achieved. The experiment was continued by replacing the first salt solution with the subsequent salt solutions in the order shown in Table 35 (Supporting Information). The same equilibration protocol was followed in each instance. For each sample, the percentage mass increase was plotted against the increase in $\mathrm{RH}$.

\section{HPLC with diode array detection (HPLC-DAD)}

Quantification of the major phenolic compounds in all samples were performed by HPLC-DAD using a validated method developed specifically for $C$. genistoides [48]. The instrument consisted of an Agilent 1200 series system with an in-line degasser, autosampler, column thermostat, quaternary pump, and diode array detector (Agilent Technologies Inc.). Separation was achieved on a Kinetex column $(150 \times 4.6 \mathrm{~mm}$ ID, $2.6 \mu \mathrm{m}$ dp; Phenomenex $)$ maintained at $30^{\circ} \mathrm{C}$, with the mobile phase consisting of $(A) 1 \%$ aqueous formic acid (v/v), (B) methanol, and (C) acetonitrile at a flow rate of $1.0 \mathrm{~mL} / \mathrm{min}$. Multi-linear gradient elution was carried out as follows: $0 \mathrm{~min}(95.0 \% \mathrm{~A}, 2.5 \% \mathrm{~B}, 2.5 \% \mathrm{C}), 5 \mathrm{~min}(95.0 \% \mathrm{~A}$, $2.5 \% \mathrm{~B}, 2.5 \% \mathrm{C}), 45 \mathrm{~min}(75 \% \mathrm{~A}, 12.5 \% \mathrm{~B}, 12.5 \% \mathrm{C}), 55 \mathrm{~min}(50 \%$ A, $25.0 \%$ B, $25.0 \%$ C), 56 min ( $50 \%$ A, $25.0 \%$ B, $25.0 \%$ C), 57 min (95.0\% A, 2.5\% B, 2.5\% C), $65 \min (95.0 \%$ A, 2.5\% B, 2.5\% C). UV-Vis spectra were recorded at $200-700 \mathrm{~nm}$, with selective wavelength monitoring at $288 \mathrm{~nm}$ (benzophenones) and $320 \mathrm{~nm}$ (xanthones). The quantification of the compounds was based on 6-point calibration curves, spanning expected concentration ranges. IDG and isomangiferin were quantified using response factors vs. I3G and mangiferin, respectively. Ascorbic acid was added to samples prior to analysis to prevent oxidation of compounds. After mixing, the samples and standard mixtures were filtered using $0.45 \mu \mathrm{m}$ Millex-HV syringe filters (Merck).

\section{Data analysis}

Target compound degradation during the 12-wk storage period was modeled using the zero order, first order, second order, and fractional conversion models [49]. Kinetic parameters were estimated by application of the models with time as independent variable for each experimental replicate, using the NLIN procedure of SAS Version 9.4 (SAS Institute Inc.). Model evaluation and selection were based on the adjusted coefficient of determination $\left(R_{\text {adj }}^{2}\right)$.

\section{Supporting Information}

Supporting information can be found in the online version of this article. Included are trans-epithelial electrical resistance data for the ex vivo transport experiments; compositions of the saturated salt solutions for moisture sorption analysis; physicochemical attributes of the major compounds relevant to the Lipinski rule of 5 criteria, and a description of the quantification of D-pinitol content in the extract and fractions.

\section{Contributors' Statement}

Conception and design of the work: N. Miller, C.J. Malherbe, J.H. Hamman, M. Aucamp, E. Joubert; data collection: N. Miller, W. Gerber, M. Aucamp; design of the study: N. Miller, C.J. Malherbe, J.H. Hamman, E. Joubert; analysis and interpretation of the data: N. Miller, W. Gerber, C.J. Malherbe, J.H. Hamman, M. Aucamp, M. van der Rijst, E. Joubert; statistical analysis: M. van der Rijst; drafting of manuscript: N. Miller, C. J. Malherbe, J.H. Hamman, E. Joubert; critical revision of the manuscript: N. Miller, W. Gerber, C.J. Malherbe, J.H. Hamman, M. Aucamp, M. van der Rijst, E. Joubert.

Acknowledgements

Grants by the National Research Foundation of South Africa (NRF grant 106988 to CJM; NRF Incentive funding grant 85277; and NRF/JSPS grant 108667 to Ej; NRF-DST Professional Development Program grant 104908 for a doctoral scholarship to NM).

\section{Conflict of Interest}

The authors declare that they have no conflict of interest.

\section{References}

[1] Bohn T, McDougall G], Alegría A, Alminger M, Arrigoni E, Aura AM, Brito C, Cilla A, El SN, Karakaya S, Martínez-Cuesta MC, Santos CN. Mind the gap-deficits in our knowledge of aspects impacting the bioavailability of phytochemicals and their metabolites - a position paper focusing on carotenoids and polyphenols. Mol Nutr Food Res 2015; 59: 1307-1323 
[2] Lopes CM, Bettencourt C, Rossi A, Buttini F, Barata P. Overview on gastroretentive drug delivery systems for improving drug bioavailability. Int J Pharm 2016; 510: 144-158

[3] Riccardi G, Capaldo B, Vaccaro O. Functional foods in the management of obesity and type 2 diabetes. Curr Opin Clin Nutr Metab Care 2005; 8: 630-635

[4] Ghani U. Re-exploring promising $\alpha$-glucosidase inhibitors for potential development into oral anti-diabetic drugs: finding needle in the haystack. Eur J Med Chem 2015; 103: 133-162

[5] Beelders T, Brand DJ, De Beer D, Malherbe C], Mazibuko SE, Muller CJF, Joubert E. Benzophenone $C$ - and O-glucosides from Cyclopia genistoides (Honeybush) inhibit mammalian $\alpha$-glucosidase. J Nat Prod 2014; 77: 2694-2699

[6] Bosman SC, De Beer D, Beelders T, Willenburg EL, Malherbe C], Walczak $B$, Joubert E. Simultaneous optimisation of extraction of xanthone and benzophenone $\alpha$-glucosidase inhibitors from Cyclopia genistoides and identification of superior genotypes for propagation. J Funct Foods 2017; 33: 21-31

[7] Miller N, Malherbe C], Joubert E. Xanthone- and benzophenone-enriched nutraceutical: development of a scalable fractionation process and effect of batch-to-batch variation of the raw material (Cyclopia genistoides). Sep Purif Technol 2020; 237: 116465

[8] Bock C, Waldmann KH, Ternes W. Mangiferin and hesperidin metabolites are absorbed from the gastrointestinal tract of pigs after oral ingestion of a Cyclopia genistoides (honeybush tea) extract. Nutr Res 2008; 28 : 879-891

[9] Geodakyan SV, Voskoboinikova IV, Tjukavkina NA, Kolhir VK, Kolesnik YA, Zjuzin VA, Glyzin VI, Sokolov SJ. Experimental pharmacokinetics of biologically active plant phenolic compounds. I. Pharmacokinetics of mangiferin in the rat. Phytother Res 1992; 6: 332-334

[10] Hou S, Wang F, Li Y, Li Y, Wang M, Sun D, Sun C. Pharmacokinetic study of mangiferin in human plasma after oral administration. Food Chem 2012; 132: 289-294

[11] Mortimer MF. Isolation and identification of compounds conferring phytoestrogenic activity to Cyclopia extracts [Master's dissertation]. Stellenbosch: Stellenbosch University; 2014

[12] Raaths M. In vitro evaluation of the enzyme inhibition and membrane permeation properties of benzophenones extracted from honeybush [Master's dissertation]. Potchefstroom: North-West University; 2016

[13] Tian X, Xu Z, Li Z, Ma Y, Lian S, Guo X, Hu P, Gao Y, Huang C. Pharmacokinetics of mangiferin and its metabolite-norathyriol, Part 2: Influence of UGT, CYP450, P-gp, and enterobacteria and the potential interaction in Rhizoma Anemarrhenae decoction with timosaponin B2 as the major contributor. Biofactors 2016; 42: 545-555

[14] De Beer D, Pauck CE, Aucamp M, Liebenberg W, Stieger N, van der Rijst $M$, Joubert E. Phenolic and physicochemical stability of a functional beverage powder mixture during storage: effect of the microencapsulant inulin and food ingredients. J Sci Food Agric 2018; 98: 2925-2934

[15] Balimane PV, Han YH, Chong S. Current industrial practices of assessing permeability and P-glycoprotein interaction. AAPS J 2006; 8: E1-E13

[16] Bernardi S, Del Bo' C, Marino M, Gargari G, Cherubini A, Andrés-Lacueva C, Hidalgo-Liberona N, Peron G, González-Dominguez R, Kroon P, Kirkup B, Porrini M, Guglielmetti S, Riso P. Polyphenols and intestinal permeability: rationale and future perspectives. J Agric Food Chem 2020; 68: 1816-1829

[17] Dahan A, Miller JM, Amidon GL. Prediction of solubility and permeability class membership: provisional BCS classification of the world's top oral drugs. AAPS J 2009; 11: 740-746

[18] Bhushani JA, Karthik P, Anandharamakrishnan C. Nanoemulsion-based delivery system for improved bioaccessibility and Caco-2 cell monolayer permeability of green tea catechins. Food Hydrocoll 2016; 56: 372-382

[19] Sjöberg Å, Lutz M, Tannergren C, Wingolf C, Borde A, Ungell AL. Comprehensive study on regional human intestinal permeability and predic- tion of fraction absorbed of drugs using the Ussing chamber technique. Eur J Pharm Sci 2013; 48: 166-180

[20] Palumbo P, Picchini U, Beck B, Van Gelder ], Delbar N, De Gaetano A. A general approach to the apparent permeability index. J Pharmacokinet Pharmacodyn 2008; 35: 235-248

[21] Lin X, Skolnik S, Chen X, Wang J. Attenuation of intestinal absorption by major efflux transporters: quantitative tools and strategies using a Caco2 model. Drug Metab Dispos 2011; 39: 265-274

[22] Gerber W, Hamman JH, Steyn JD. Excipient-drug pharmacokinetic interactions: effect of disintegrants on efflux across excised pig intestinal tissues. J Food Drug Anal 2018; 26: S115-S124

[23] Lohner K, Schnäbele K, Daniel H, Oesterle D, Rechkemmer G, Göttlicher $\mathrm{M}$, Wenzel $\mathrm{U}$. Flavonoids alter P-gp expression in intestinal epithelial cells in vitro and in vivo. Mol Nutr Food Res 2007; 51: 293-300

[24] Khurana RK, Bansal AK, Beg S, Burrow A], Katare OP, Singh KK, Singh B. Enhancing biopharmaceutical attributes of phospholipid complexloaded nanostructured lipidic carriers of mangiferin: systematic development, characterization and evaluation. Int J Pharm 2017; 518: 289306

[25] Mchunu NPN. In vitro assessment of cytochrome P450 and drug transporters modulation by polyphenolic constituents of Cyclopia genistoides [Master's dissertation]. Richard's Bay: University of Zululand; 2019

[26] Alqahtani S, Mohamed LA, Kaddoumi A. Experimental models for predicting drug absorption and metabolism. Expert Opin Drug Metab Toxicol 2013; 9: 1241-1254

[27] Ávila-Gálvez MÁ, González-Sarrías A, Espín JC. In vitro research on dietary polyphenols and health: a call of caution and a guide on how to proceed. J Agric Food Chem 2018; 66: 7857-7858

[28] Gu PC, Wang L, Han MN, Peng J, Shang JC, Pan YQ, Han WL. Comparative pharmacokinetic study of mangiferin in normal and alloxan-induced diabetic rats after oral and intravenous administration by UPLC-MS/MS. Pharmacology 2019; 103: 30-37

[29] Liu H, Wu B, Pan G, He L, Li Z, Fan M, Jian L, Chen M, Wang K, Huang C. Metabolism and pharmacokinetics of mangiferin in conventional rats, pseudo-germ-free rats, and streptozotocin-induced diabetic rats. Drug Metab Dispos 2012; 40: 2109-2118

[30] Lipinski CA, Lombardo F, Dominy BW, Feeney PJ. Experimental and computational approaches to estimate solubility and permeability in drug discovery and development settings. Adv Drug Deliv Rev 1997; 23: 3-25

[31] Seelig A. A general pattern for substrate recognition by P-glycoprotein. Eur ] Biochem 1998; 251: 252-261

[32] Vyas A, Syeda K, Ahmad A, Padhye S, Sarkar FH. Perspectives on medicinal properties of mangiferin. Mini-Reviews Med Chem 2012; 12: 412 425

[33] Núñez-Sellés AJ. Antioxidant therapy: Myth or reality? J Braz Chem Soc 2005; 16: 699-710

[34] Vazquez-Olivo G, Antunes-Ricardo M, Gutiérrez-Uribe JA, Osuna-Enciso T, León-Félix J, Heredia JB. Cellular antioxidant activity and in vitro intestinal permeability of phenolic compounds from four varieties of mango bark (Mangifera indica L.). J Sci Food Agric 2019; 99: 3481-3489

[35] Miller N, Bosman SC, Malherbe C], De Beer D, Joubert E. Membrane selection and optimisation of tangential flow ultrafiltration of Cyclopia genistoides extract for benzophenone and xanthone enrichment. Food Chem 2019; 292: 121-128

[36] Yang G, Bibi S, Du M, Suzuki T, Zhu MJ. Regulation of the intestinal tight junction by natural polyphenols: a mechanistic perspective. Crit Rev Food Sci Nutr 2017; 57: 3830-3839

[37] Ulluwishewa D, Anderson RC, McNabb WC, Moughan PJ, Wells JM, Roy NC. Regulation of tight junction permeability by intestinal bacteria and dietary components. J Nutr 2011; 141: 769-776

[38] Lerner A, Matthias T. Changes in intestinal tight junction permeability associated with industrial food additives explain the rising incidence of autoimmune disease. Autoimmun Rev 2015; 14: 479-489 
[39] Murikipudi V, Gupta P, Sihorkar V. Efficient throughput method for hygroscopicity classification of active and inactive pharmaceutical ingredients by water vapor sorption analysis. Pharm Dev Technol 2013; 18: 348-358

[40] Huynh-Ba K, Zahn M. Understanding ICH Guidelines applicable to Stability Testing. In: Huynh-Ba K, ed. Handbook of Stability Testing in pharmaceutical Development. New York: Springer Science \& Business Media; 2009: 21-42

[41] ICH. Stability testing of new drug substances and products Q1A(R2). ICH Harmon Tripart Guidel 2003. Accessed August 8, 2019 at: https://www. ich.org/fileadmin/Public_Web_Site/ICH_Products/Guidelines/Quality/ Q1A_R2/Step4/Q1A_R2_Guideline.pdf

[42] Beelders T, De Beer D, Ferreira D, Kidd M, Joubert E. Thermal stability of the functional ingredients, glucosylated benzophenones and xanthones of honeybush (Cyclopia genistoides), in an aqueous model solution. Food Chem 2017; 233: 412-421

[43] Beelders T, De Beer D, Joubert E. Thermal degradation kinetics modeling of benzophenones and xanthones during high-temperature oxidation of Cyclopia genistoides (L.) Vent. plant material. J Agric Food Chem 2015; 63: 5518-5527
[44] Hubatsch I, Ragnarsson EGE, Artursson P. Determination of drug permeability and prediction of drug absorption in Caco-2 monolayers. Nat Protoc 2007; 2: 2111-2119

[45] Wahlang B, Pawar YB, Bansal AK. Identification of permeability-related hurdles in oral delivery of curcumin using the Caco-2 cell model. Eur J Pharm Biopharm 2011; 77: 275-282

[46] Human C, De Beer D, Aucamp M, Marx IJ, Malherbe C], Viljoen-Bloom M, van der Rijst M, Joubert E. Preparation of rooibos extract-chitosan microparticles: physicochemical characterisation and stability of aspalathin during accelerated storage. LWT Food Sci Technol 2020; 117: 108653

[47] Hassel RL. Moisture sorption analysis of pharmaceuticals. TA Instruments 2006; 1-15. Accessed November 14, 2019 at: http://www. tainstruments.com/pdf/literature/TA329a Moisture Sorption Analysis of Pharmaceuticals.pdf

[48] Beelders T, De Beer D, Stander MA, Joubert E. Comprehensive phenolic profiling of Cyclopia genistoides (L.) Vent. by LC-DAD-MS and -MS/MS reveals novel xanthone and benzophenone constituents. Molecules 2014; 19: $11760-11790$

[49] van Boekel MAJS. Kinetic modeling of food quality: a critical review. Compr Rev Food Sci Food Saf 2008; 7: 145-158 